\title{
PERAMALAN BUTUHAN HIDUP MINIMUM MENGGUNAKAN AUTOMATIC CLUSTERING DAN FUZZY LOGICAL RELATIONSHIP
}

\author{
Yusuf Priyo Anggodo' ${ }^{1}$, Wayan Firdaus Mahmudy ${ }^{2}$ \\ Teknik Informatika, Fakultas Ilmu Komputer, Universitas Brawijaya \\ e-mail: ${ }^{1}$ anggodoyusuf1950@gmail.com, ${ }^{2}$ wayanfm@ub.ac.id
}

(Naskah masuk: 20 Mei 2016, diterima untuk diterbitkan: 20 Juni 2016)

\begin{abstract}
Abstrak
Kebutuhan hidup minimum (KHM) adalah standar kebutuhan seorang pekerja atau lanjang untuk dapat hidup layak secara fisik untuk kebutuhan satu bulan. Selain itu KHM berpengaruh terhadap upah minum provinsi dan kota. Oleh karena itu diperlukan suatu peramalan KHM untuk mengetahui nilai KHM di tahun yang akan datang. Peramalan ini bermanfaat untuk perusahaan dalam merencanakan keuangan perusahaan tahun depan. Dalam melakukan peramalan KHM menggunakan metode automatic clustering dan fuzzy logical relationship. Automatic clustering digunakan untuk membentuk sub-interval dari data time series yang ada. Sedangkan fuzzy logical relationship digunakan untuk melakukan peramalan KHM berdasarkan relasi fuzzy yang telah dikelompokan. Automatic clustering dapat menghasilkan cluster-cluster yang sangat baik sehingga dalam melakukan peramalan dalam fuzzy logical relationship memberikan akurasi yang tinggi. Dalam menghitung kesalahan menggunakan mean squere error (MSE), nilai kesalahan semakin berkurang ketika diterapkan automatic clustering dalam fuzzy logical relationship. Hasil peramalan memiliki nilai koefisien korelasi yang hampir mendekati satu.
\end{abstract}

Kata Kunci: kebutuhan hidup minimum, automatic clustering, dan fuzzy logical relationship.

\begin{abstract}
Minimum living needs (KHM) is a standard requirement for a worker or naked physically can live well for the needs of one month. Additionally KHM effect on the wages of provincial and municipal drinking. Therefore we need a forecasting MIC to determine the value of the MIC in the coming year. Forecasting is beneficial for the company in the financial planning company next year. In forecasting the KHM using automatic clustering and fuzzy logical relationship. Automatic clustering is used to form a sub-interval of the existing time series data. While fuzzy logical relationship is used for forecasting KHM based fuzzy relationships that have been grouped. Automatic clustering clusters can produce very good so doing forecasting in fuzzy logical relationship provides high accuracy. In calculating errors using squere mean error (MSE), the error decreases when applied to automatic clustering in the fuzzy logical relationship. Forecasting results have a correlation coefficient values close to one.
\end{abstract}

Keywords: minimum living needs, automatic clustering, dan fuzzy logical relationship.

\section{PENDAHULUAN}

Kebutuhan hidup minimum atau layak (KHM) sudah diatur dalam peraturan Menteri Tenaga Kerja dan Transmigrasi yaitu "Kebutuhan hidup layak yang selanjutnya disingkat KHL adalah standar kebutuhan seorang pekerja atau buruh lajang untuk dapat hidup layak secara fisik untuk kebutuhan 1 (satu) bulan". Selain itu pada pasal 6 sampai 8 juga mengatur bahwa KHM digunakan sebagai parameter untuk menentukan upah minimum provinsi dan kota. Dari informasi hasil peramalan kebutuhan hidup minimum dapat dijadikan sebagai perancangan keuangan perusahaan kedepannya.

Peramalan sudah biasa dilakukan banyak orang untuk mengetahui peristiwa yang akan terjadi pada masa yang akan datang dengan melihat aktivitas yang telah terjadi sebelumnya (Chen et al, 2016). Seperti peramalan suhu, curah hujan, stok barang, gempa bumi, dsb. Peramalan secara tradisional tidak memperhatikan data sebelumnya dan lebih bersifat kualitatif bukan kuantatif. Pada permasalahan peramalan kebutuhan hidup minimum belum ada penelitian padahal peramalan kebutuhan hidup minimum ini akan bermanfaat untuk perusahaan.

Ada beberapa metode peramalan yang menggunakan pendekatan kuantatif, salah satunya fuzzy logic (Wang et al, 2014). Metode Fuzzy time series pertama kali diterapkan oleh Song dan Chissom (1993a, 1993b, 1994) untuk menyelesaikan permasalahan peramalan dengan cara melihat data sebelumnya untuk membentuk model fuzzy time series. Model Song dan Chissom's (1993a, 1993b, 1994) menggunakan 
min-max operasi untuk meramalkan jumlah pendaftar di Universitas Alabama. Selain itu ada model fuzzy lain, yaitu model fuzzy time series Chen et al's yang lebih simpel juga diterapkan untuk meramalkan jumlah pendaftar di Universitas Alabama (Chen dan Tunawijaya, 2010).

Pada tahun sebelumnya, beberapa penelitian yang berfokus pada fuzzy time series untuk penyelesaian permasalahan peramalan antara lain (Liu et al, 2011; Qiu et al, 2011; Aznarte et al, 2012; Chen dan Tunawaijaya, 2011; Saha dan Bandyopadyay, 2013; Hung dan Kang, 2014; Wang dan Liu, 2015; Garcia dan Flores, 2016; Qiu et al, 2015; Cheng et al, 2016).

Fuzzy time series dikembangkan dengan beberapa metode dapat menyelesaikan permasalahan peramalan jumlah mahsiswa Universitas Alabama dengan akurasi yang tinggi dan waktu komputasi lebih efektif (Liu et al, 2011). (Qiu et al, 2011) melakukan generalisasi model fuzzy time series pada permasalahan peramalan pada model Song dan Chissom, model Chen, dan model Lee at al sehingga didapatkan hasil yang lebih baik. Peramalan menggunakan fuzzy time series dapat menyelesaikan permasalahan keuangan yang komplek (Aznarte et al, 2012). Dari beberapa penelitian tersebut dapat kita simpulkan bahwa fuzzy time series dapat menyelesaikan permasalahan peramalan dengan baik.

Penggunaan metode automatic clustering dirasa efektif dalam melakukan klasifikasi data sebelumnya, pada metode fuzzy time series untuk menyelesaikan permasalahan peramalan (Chen dan Tunawijaya, 2011). Pada penelitian He dan Tan (2012) automatic clustering dapat mengklasifikasikan data yang komplek sehingga algoritma genetika dapat melakukan pencarian data yang lebih baik. Generalisasi metode automatic clustering pada permasalahan multiobjective dapat memberikan hasil yang lebih baik dalam beberapa kombinasi metode (Saha dan Bandyopadyay, 2013). Pada penelitian Hung dan Kang (2014) metode autmatic clustering dapat melakukan klasifikasi simulasi kontruksi dengan baik. Selain itu pada penelitian Askari et al (2015) penggunaan metode klasifikasi clustering fuzzy time series pada fuzzy time series menghasilkan nilai error yang kecil juga dapat mengatasi ketidakpastian beberapa variabel. Sedangkan penggunaan metode klasifikasi menggunakan metode automatic dan axiomatic clustering (AFS) memberikan hasil yang lebih signifikan dari sebelumnya (Wang dan Liu, 2015. Pada kasus metaheuristik metode automatic sangat menolong dalam melakukan klasifikasi data (Garcia dan Flores, 2016). Dari penelitian yang telah dilakukan metode automatic clustering cukup efektif dan sangat membantu dalam melakukan klasifikasi data dengan kombinasi berbagai metode untuk penyelesaiannya. Penggunaan automatic clustering mendapatkan hasil akurasi lebih signifikan dibandingkan tanpa penggunakan klasifikasi data.

Metode peramalan high-order fuzzy logical relationship (Chen dan Chen, 2011) dapat menyelesaikan permalahan TAIEX, sedangkan pada penelitian Chen dan Chen (2015) pada permasalahan yang sama digunakan metode fuzzy logical relationship yang dioptimalkan dengan penggunaan second-order dan probabilitas trenfuzzy pada fuzzy logical relationship (Chen dan Chen, 2015). Penggunaan high-order, secondorder dan tren-fuzzy dalam fuzzy logical relationship mendapatkan hasil akurasi yang tidak terlalu signifikan. Peramalan juga dilakukan untuk meramalkan jumlah mahasiswa Universitas Alabama menggunakan automatic clustering dan fuzzy logical relationship yang dilakukan generalisasi mendapatkan error yang lebih rendah (Qiu et al, 2015). Pada kasus yang sama penelitian Cheng et al (2015; 2016) menggunakan fuzzy logical relationship yang dikembangkan dengan beberapa metode lain mendapatkan error yang lebih rendah dari penelitian yang pernah ada. Dari penelitian-penelitian dapat disimpulkan bahwa fuzzy logical relationship dapat menyelesaikan permasalahan peramalan dengan berbagai kombonasi metode atau berdiri sendiri.

Dalam penelitian ini akan dilakukan peramalan menggunakan automatic clustering dan fuzzy logical relationships untuk meramalkan kebutuhan hidup minimum. Tahap pertama metode automatic clustering akan digunakan untuk mengklasifikasikan histori data kebutuhan hidup minimum sesuai dengan pajang intervalnya. Interval terbentuk dari $\mathrm{p}$ sub-interval, dimana $\mathrm{p} \geq 1$. Pembentukan interval tak statis ini dapat menghasilkan error yang lebih kecil (Garcia, 2016; Qiu et al, 2015). Peramalan dilakukan dengan metode fuzzy logical relationship. Metode ini terbukti efektif dengan dihasilkan akurasi yang lebih baik dari metode lainnya (Qiu et al, 2015; Cheng et al, 2016).

Yang menjadi fokus pada penelitian ini, pertama mengkaji tentang dasar fuzzy time series. Kedua klasifikasi histori data kebutuhan hidup minimum menggunakan automatic clustering. Ketiga melakukan peramalan kebutuhan hidup minimum menggunakan automatic clustering dan fuzzy logical relationships. Keempat menghitung Mean Squere Error (MSE) hasil peramalan menggunakan metode automatic clustering dan fuzzy logical ralationship pada kasus peramalan kubutuhan hidup minimum.

\section{METODE}

perancangan sistem dalam permasalahan peralaman kebutuhan hidup minimum (KHM) menggunakan automatic clustering dan fuzzy logical relationship dilakukan beberapa tahapan, pertama dengan melakukan pengumpulan data. 
Data yang diambil adalah data sekunder dari Badan Pusat Statistika (Badan Pusat Statistik, 2016). Pada Tabel 1 ditunjukan data kebutuhan hidup minimum provinsi Jawa Timur selama sebulan (rupiah) dari tahun 2005 sampai tahun 2015.

Tabel 2.1. Data kebutuhan hidup minimum provinsi Jawa Timur

\begin{tabular}{cccc}
\hline Tahun & KHM & Tahun & KHM \\
\hline 2005 & 339277 & 2011 & 731635 \\
2006 & 580054 & 2012 & 731635 \\
2007 & 458755 & 2013 & 825000 \\
2008 & 544157 & 2014 & 825000 \\
2009 & 706698 & 2015 & 825000 \\
2010 & 856888 & & \\
\hline
\end{tabular}

Algoritma automatic clustering digunakan untuk melakukan klasifikasi data numerik berdasarkan interval (Wand dan Liu, 2015). Interval yang dimaksud adalah jarak, sehingga data numerik diklasifikasikan berdasarkan jarak terdekat. Semakin kecil jarak antara dua elemen data numerik maka semakin tinggi kesamaannya (Qiu et al, 2015). Pada Gambar 2.1 ditunjukan alur kerja dari metode automatic clustering.

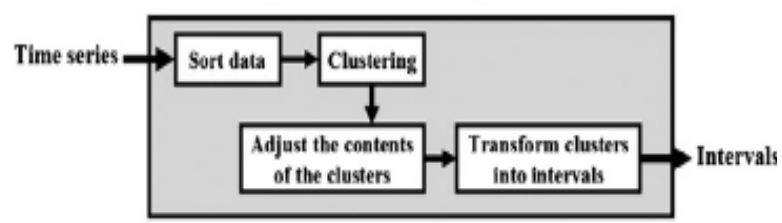

Gambar 2.1. Alur kerja metode automatic clustering (Qiu et al, 2015).

Berikut adalah langkah-langkah algoritma automatic clustering (Wang dan Liu, 2015; Chen dan Tunawijaya):

Langkah 1: pertama urutkan data numerik menaik, asumsikan tidak ada data yang sama.

$$
\mathrm{d}_{1}, \mathrm{~d}_{2}, \mathrm{~d}_{3}, \ldots, \mathrm{d}_{\mathrm{i}}, \ldots, \mathrm{d}_{\mathrm{n}} .
$$

Lalu hitung avarage_diff:

$$
\text { average_diff }=\frac{\sum_{i=1}^{n-1}\left(d_{i+1}-d_{i}\right)}{n-1}
$$

dimana avarage_diff adalah rata-rata dari data numerik dan $\mathrm{d}_{1}, \mathrm{~d}_{1}, \ldots, \mathrm{d}_{\mathrm{n}}$. adalah data numerik yang telah diurutkan.

Langkah 2: mengambil data numerik pertama (yaitu datum terkecil) untuk ditempatkan ke current cluster atau perlu membuat cluster baru berdasarkan prinsip-prinsip berikut:

Prinsip 1: asumsikan current cluster adalah cluster pertama dan hanya ada satu datum yaitu $d_{1}$ serta menganggap bahwa $d_{2}$ adalah datum yang berdekatan dengan $\mathrm{d}_{1}$, ditampilkan sebagai berikut:

$$
\left\{\mathrm{d}_{1}\right\}, \mathrm{d}_{2}, \mathrm{~d}_{3}, \ldots, \mathrm{d}_{\mathrm{i}}, \ldots, \mathrm{d}_{\mathrm{n}} .
$$

if $\mathrm{d}_{2}-\mathrm{d}_{1} \leq$ avarage_diff, maka masukan $\mathrm{d}_{2}$ ke cluster saat ini yang beranggotakan $\mathrm{d}_{1}$, jika tidak buat cluster baru yang beranggotakan $\mathrm{d}_{2}$. Prinsip 2: asumsikan bahwa current cluster bukan cluster pertama dan $\mathrm{d}_{\mathrm{j}}$ adalah datum satu-satunya di current cluster. Asumsikan $\mathrm{d}_{\mathrm{k}}$ adalah datum yang berdekatan dengan datum $\mathrm{d}_{\mathrm{j}}$ dan $\mathrm{d}_{\mathrm{i}}$ adalah datum terbesar di antecedent cluster, ditampilkan sebagai berikut:

$$
\left\{d_{1}\right\}, \ldots,\left\{\ldots, \mathrm{d}_{\mathrm{i}}\right\},\left\{d_{j}\right\}, d_{k}, \ldots, d n \text {. }
$$

if $\mathrm{d}_{\mathrm{k}}-\mathrm{d}_{\mathrm{j}} \leq$ avarage_diff dan $\mathrm{d}_{\mathrm{k}}-\mathrm{d}_{\mathrm{j}} \leq \mathrm{d}_{\mathrm{j}}-\mathrm{d}_{\mathrm{i}}$, maka masukan $\mathrm{d}_{\mathrm{k}}$ ke cluster yang dimiliki $\mathrm{d}_{\mathrm{j}}$, jika tidak buat cluster baru yang beranggotakan $\mathrm{d}_{\mathrm{k}}$.

Prinsip 3: asumsikan bahwa current cluster bukan cluster pertama dan asumsikan bahwa $\mathrm{d}_{\mathrm{i}}$ merupakan datum terbesar di current cluster. Asumsikan bahwa $\mathrm{d}_{\mathrm{j}}$ adadalah datum terdekat dengan $d_{i}$

$$
\left\{d_{1}\right\}, \ldots,\{\ldots\},\left\{\ldots, d_{i}\right\}, d_{j}, \ldots, d n .
$$

if $\mathrm{d}_{\mathrm{j}}-\mathrm{d}_{\mathrm{i}} \leq$ avarage_diff dan $\mathrm{d}_{\mathrm{j}}-\mathrm{d}_{\mathrm{i}} \leq$ cluster_diff, maka masukan $\mathrm{d}_{\mathrm{j}}$ ke dalam cluster yang beranggotakan $\mathrm{d}_{\mathrm{i}}$. Jika tidak buat cluster baru untuk $\mathrm{d}_{\mathrm{j}}$. Perhitungan cluster_diff ditunjukan pada Persamaan 2.2.

$$
\text { cluster_diff }=\frac{\sum_{i=1}^{n-1}\left(c_{i+1}-c_{i}\right)}{n-1},(2.2)
$$

dimana cluster_diff adalah rata-rata dari current cluster dan $\mathrm{c}_{1}, \mathrm{c}_{2}, \ldots \mathrm{c}_{\mathrm{n}}$ adalah data di dalam current cluster.

Langkah 3: berdasarkan hasil klarifikasi langkah 2, sesuai isi cluster sesuai prinsip berikut:

Prinsip 1: jika dalam cluster terdapat lebih dari dua datum, maka pertahankan datum terkecil dan terbesar serta hapus datum yang lain.

Prinsip 2: jika dalam cluster terdapat dua datum, maka pertahankan semuanya.

Prinsip 3: jika dalam cluster hanya terdapat satu datum $\mathrm{d}_{\mathrm{q}}$, maka menambahkan datum dengan nilai $\mathrm{d}_{\mathrm{q}}$-avarage_diff dan $\mathrm{d}_{\mathrm{q}}+$ avarage_diff ke dalam cluster. Tetapi juga harus menyesuaikan dengan situasi berikut:

Situasi 1: jika cluster pertama, maka hapus $\mathrm{d}_{\mathrm{q}}$-avarage_diff dan pertahankan $\mathrm{d}_{\mathrm{q}}$. Situasi 2: jika cluster terahkir, maka hapus $\mathrm{d}_{\mathrm{q}}+$ avarage_diff dan pertahankan $\mathrm{d}_{\mathrm{q}}$.

Situasi 3: jika $\mathrm{d}_{\mathrm{q}}$-avarage_diff lebih kecil dari nilai datum terkecil di antecedent cluster, maka Prinsip 3 tidak berlaku. 
Langkah 4: asumsikan hasil langkah 3 sebagai berikut :

$\left\{d_{1}, d_{2}\right\},\left\{d_{3}, d_{4}\right\},\left\{d_{5}, d_{6}\right\}, \ldots,\left\{d_{r}\right\},\left\{d_{s}, d_{t}\right\}, \ldots$ . , $\left\{\mathrm{d}_{\mathrm{n}-1}, \mathrm{~d}_{\mathrm{n}}\right\}$.

Mengubah hasil cluster ke dalam cluster yang berdekatan melalui sub langkah berikut:

4.1 ubah cluster pertama $\left\{\mathrm{d}_{1}, \mathrm{~d}_{2}\right\}$ menjadi interval $\left[\mathrm{d}_{1}, \mathrm{~d}_{2}\right)$.

4.2 jika current interval $\left[\mathrm{d}_{\mathrm{i}}, \mathrm{d}_{\mathrm{j}}\right.$ ) dan current cluster $\left\{\mathrm{d}_{\mathrm{k}}, \mathrm{d}_{1}\right\}$, maka:

(1) if $\mathrm{d}_{\mathrm{j}} \geq \mathrm{d}_{\mathrm{k}}$, maka bentuk sebuah interval $\left[\mathrm{d}_{\mathrm{j}}\right.$, $\left.\mathrm{d}_{1}\right)$. interval $\left[\mathrm{d}_{\mathrm{j}}, \mathrm{d}_{\mathrm{l}}\right)$ sekarang menjadi current interval dan next cluster $\left\{\mathrm{d}_{\mathrm{m}}, \mathrm{d}_{\mathrm{n}}\right\}$ menjadi current cluster.

(2) if $\mathrm{d}_{\mathrm{j}}<\mathrm{d}_{\mathrm{k}}$, maka ubah current cluster $\left\{\mathrm{d}_{\mathrm{k}}\right.$, $\left.\mathrm{d}_{\mathrm{l}}\right\}$ menjadi interval $\left[\mathrm{d}_{\mathrm{k}}, \mathrm{dl}\right)$ dan buat interval baru $\left[\mathrm{d}_{\mathrm{j}}, \mathrm{d}_{\mathrm{k}}\right.$ ) dari interval $\left[\mathrm{d}_{\mathrm{i}}, \mathrm{d}_{\mathrm{j}}\right.$ ) dan $\left[\mathrm{d}_{\mathrm{k}}, \mathrm{d}_{\mathrm{l}}\right)$. Sekarang $\left[\mathrm{d}_{\mathrm{k}}, \mathrm{d}_{\mathrm{l}}\right)$ menjadi current interval dan next cluster $\left\{\mathrm{d}_{\mathrm{m}}, \mathrm{d}_{\mathrm{n}}\right\}$ menjadi current cluster. Jika sekarang current interval $\left[\mathrm{d}_{\mathrm{i}}, \mathrm{d}_{\mathrm{j}}\right.$ ) dan current cluster adalah $\left\{\mathrm{d}_{\mathrm{k}}\right\}$, maka ubah current interval $\left[\mathrm{d}_{\mathrm{i}}, \mathrm{d}_{\mathrm{j}}\right)$ menjadi $\left[\mathrm{d}_{\mathrm{i}}, \mathrm{d}_{\mathrm{k}}\right)$. Sekarang $\left[\mathrm{d}_{\mathrm{i}}, \mathrm{d}_{\mathrm{k}}\right)$ adalah current interval dan next interval menjadi current inteval.

4.3 ulangi sub langkah 4.1 dan 4.2 sampai semua cluster menjadi interval.

Langkah 5: hasil langkah 4 bagi interval ke $\mathrm{p}$ sub-interval, dimana $\mathrm{p} \geq 1$.

Berdasarkan Tabel 2.1 dapat dilakukan klasifikasi data menggunakan metode automatic clustering sehingga terbentuk sebuah interval. Langkah-langkah penerapan automatic clustering sebagai berikut :

\section{Langkah 1:}

Hasil pengurutan histori data kebutuhan hidup minimum pada Tabel 2.1 tahun 2005 sampai tahun 2014 secara menaik, sebagai berikut:

339227, 458755, 544157, 580054, 706698,

$731635,731635,825000,825000,856888$.

Ketika ada dua atau lebih datum yang sama cukup dituliskan satu kali (Wang dan Liu, 2015), sehingga hasilnya adalah:

339227, 458755, 544157, 580054, 706698, $731635,825000,856888$.

Lalu hitung avarage_diff menggunakan persamaan 2.1 sebagai berikut: avarage_diff $=[(458755-339227)+$ $(544157-458755)+(580054-$ $544157)+(706698-580054)+$ $(731635-706698)+(825000-$ $731635)+(856888-825000)] / 8-1=$ $517661 / 8=73951.57$

\section{Langkah 2:}

Berdasarkan nilai avarage_diff sehingga data menaik dapat dilakukan klasifikasi sehingga diperoleh hasil klasifikasi sebagai berikut :
$\{339227\},\{458755\},\{544157,580054\}$, $\{706698,731635\},\{825000,85688\}$.

\section{Langkah 3:}

Berdasarkan hasil pada Langka 2 selanjutnya diterapkanlah 3 prinsip pada langkah 3 sehingga diperoleh hasil sebagai berikut:

[339227, 413178.6), [384803.4, 532706.6), [544157, 580054), [706698, 731635), [82500, 856888).

\section{Langkah 4:}

Berdasarkan sub-langkah Langkah 4 diperoleh hasil interval-interval sebagai berikut:

$$
\begin{array}{cc}
\mathrm{u}_{1}=[339227,413178.57) & \mathrm{U}_{5}=[580054,706698) \\
\mathrm{u}_{2}=[413178.57,532706.57) & \mathrm{U}_{6}=[706698,731635) \\
\mathrm{u}_{3}=[532706.57,544157) & \mathrm{u}_{7}=[731635,825000) \\
\mathrm{u}_{4}=[544157,580054) & \mathrm{u}_{8}=[825000,825000)
\end{array}
$$

\section{Langkah 5:}

Jika nilai $\mathrm{p}=2$, maka hasil interval pada

Langkah 4 dibagi sebanyak 2 sub-interval. Diperoleh hasilnya sebagai berikut:

$$
\begin{gathered}
\mathrm{u}_{1}=[339227,376202.78) \\
\mathrm{u}_{2}=[376202.78,413178.57) \\
\mathrm{u}_{3}=[413178.57,472942.57) \\
\mathrm{u}_{4}=[472942.57,532706.57) \\
\mathrm{u}_{5}=[532706.57,538431.78) \\
\mathrm{u}_{6}=[538431.78,544157) \\
\mathrm{u}_{7}=[544157,562105.5) \\
\mathrm{u}_{8}=[562105.5,580054)
\end{gathered}
$$

$$
\begin{aligned}
\mathrm{U}_{9} & =[580054,643376) \\
\mathrm{u}_{10} & =[643376,706698) \\
\mathrm{u}_{11} & =[706698,719166.5) \\
\mathrm{u}_{12} & =[719166.5,731635) \\
\mathrm{u}_{13} & =[731635,778317) \\
\mathrm{u}_{14} & =[778317,825000) \\
\mathrm{u}_{15} & =[825000,840944) \\
\mathrm{u}_{16} & =[840944,856888)
\end{aligned}
$$

Pada bagian ini akan dijabarkan langkahlangkah metode peramalan fuzzy logical relationships dengan klasifikasi menggunakan automatic clustering, (Cheng et al, 2016) sebagai berikut :

Langkah 1: menerapkan algoritma automatic clustering untuk klasifikasi histori data menjadi interval dan menghitung titik tengah setiap interval.

Langkah 2: Asumsikan terdapat $\mathrm{n}$ intervals, $\mathrm{u}_{1}$, $\mathrm{u}_{2}, \mathrm{u}_{3}, \ldots, \mathrm{u}_{\mathrm{n}}$. Lalu bentuk himpunan fuzzy $\mathrm{A}_{\mathrm{i}}$, dimana $1 \leq \mathrm{i} \leq \mathrm{n}$, sehingga akan terbentuk:

$$
\mathrm{A}_{1}=1 / \mathrm{u}_{1}+0.5 / \mathrm{u}_{2}+0 / \mathrm{u}_{3}+0 / \mathrm{u}_{4}+\ldots+0 / \mathrm{u}_{\mathrm{n}-1}+
$$
$0 / \mathrm{u}_{\mathrm{n}}$

$\mathrm{A}_{2}=0.5 / \mathrm{u}_{1}+1 / \mathrm{u}_{2}+0.5 / \mathrm{u}_{3}+0 / \mathrm{u}_{4}+\ldots+0 / \mathrm{u}_{\mathrm{n}}$ $1+0 / \mathrm{u}_{\mathrm{n}}$

$$
\mathrm{A}_{3}=0 / \mathrm{u}_{1}+0.5 / \mathrm{u}_{2}+1 / \mathrm{u}_{3}+0.5 / \mathrm{u}_{4}+\ldots+0 / \mathrm{u}_{\mathrm{n}}
$$
$1+0 / u_{n}$.

$$
1 / \mathrm{u}_{\mathrm{n}} \text {. }
$$$$
\mathrm{A}_{\mathrm{n}}=0 / \mathrm{u}_{1}+0 / \mathrm{u}_{2}+0 / \mathrm{u}_{3}+0 / \mathrm{u}_{4}+\ldots+0.5 / \mathrm{u}_{\mathrm{n}-1}+
$$

Langkah 3: fuzzifikasi setiap datum dari histori data menjadi himpunan fuzzy. Jika datum adalah $\mathrm{u}_{\mathrm{i}}$, dimana $1 \leq \mathrm{i} \leq \mathrm{n}$. Maka lakukan fuzzifikasi menjadi $\mathrm{A}_{\mathrm{i}}$

Langkah 4: membangun fuzzy logical relationship berdasarkan hasil fuzzifikasi dari langkah 3. Jika hasil fuzzifikasi tahun $\mathrm{t}$ dan $\mathrm{t}+1$ 
adalah $\mathrm{A}_{\mathrm{j}}$ dan $\mathrm{A}_{\mathrm{k}}$. Maka fuzzy logical relationship yang dibangun adalah $A_{j} \rightarrow A_{k}$, dimana $A_{j}$ disebut sebagai current state dan $A_{k}$ sebagai next state di fuzzy logical relationship. Dalam fuzzy logical relationship dibagi menjadi kelompokkelompok, dimana current state yang sama dimasukan dalam satu kelompok.

Langkah 5: melakukan peramalan menggunakan prinsip-prinsip berikut :

Prinsip 1: jika fuzzifikasi tahun $\mathrm{t}$ adalah $\mathrm{A}_{\mathrm{j}}$ dan ada fuzzy logical relationship di fuzzy logical relationship group, dengan kondisi:

$$
\mathrm{A}_{\mathrm{j}} \rightarrow \mathrm{A}_{\mathrm{k}} \text { (2.3) }
$$

Nilai peramalan tahun $t+1$ adalah $m_{k}$, dimana $\mathrm{m}_{\mathrm{k}}$ adalah titik tengataph dari interval $\mathrm{u}_{\mathrm{k}}$ dan nilai maksimum keanggotaan himpunan fuzzy $\mathrm{A}_{\mathrm{k}}$ dari interval $\mathrm{U}_{\mathrm{k}}$.

Prinsip 2: jika fuzzifikasi tahun $\mathrm{t}$ adalah $\mathrm{A}_{\mathrm{j}}$ dan ada fuzzy logical ralationship di fuzzy logical relationship group, dengan kondisi:

$$
A_{j} \rightarrow A_{k 1}\left(x_{1}\right), A_{k 2}\left(x_{2}\right), \ldots A_{k p}\left(x_{p}\right),(2.4)
$$

Nilai peramalan tahun $\mathrm{t}+1$ menggunakan:

$$
\frac{\mathrm{x}_{1} \times \mathrm{mk}_{1}+\mathrm{x}_{2} \times \mathrm{mk}_{2}+\ldots+\mathrm{x}_{\mathrm{p}} \times \mathrm{mk}_{\mathrm{p}}}{\mathrm{x}_{1}+\mathrm{x}_{2}+\cdots+\mathrm{x}_{\mathrm{p}}},
$$

Dimana $\mathrm{x}_{\mathrm{i}}$ adalah nomer dari fuzzy logical relationship dari $\mathrm{A}_{\mathrm{j}} \rightarrow \mathrm{A}_{\mathrm{k}}$ di fuzzy logical relationship group, $1 \leq \mathrm{i} \leq \mathrm{n} . \mathrm{mk}_{1}, \mathrm{mk}_{2}, \ldots, \mathrm{mk}_{\mathrm{p}}$ adalah titik tengah dari interval $\mathrm{uk}_{1}, \mathrm{uk}_{2}, \ldots, \mathrm{uk}_{\mathrm{p}}$ dan nilai maksimum keanggotaan himpunan fuzzy $\mathrm{Ak}_{1}, \mathrm{Ak}_{2}, \ldots, \mathrm{Ak}_{\mathrm{p}}$ dari interval $\mathrm{Uk}_{1}, \mathrm{Uk}_{2}$, ...,Uk .

Prinsip 3: jika fuzzifikasi tahun $\mathrm{t}$ adalah $\mathrm{A}_{\mathrm{j}}$ dan ada fuzzy logical relationship di fuzzy logical retlationship group, dengan kondisi:

$$
A_{j} \rightarrow \#, \text { (2.6) }
$$

Dimana nilai \# adalah kosong. Nilai peramalan tahun $\mathrm{t}+1$ adalah $\mathrm{m}_{\mathrm{j}}$, dimana $\mathrm{m}_{\mathrm{j}}$ adalah titik tengah dari interval $\mathrm{t}+1$ dan nilai maksimum keanggotaan himpunan fuzzy $\mathrm{A}_{\mathrm{j}}$ dari interval $\mathrm{U}_{\mathrm{j}}$.

Dalam penerapan peramalan menggunakan automatic clustering dan fuzzy logical relationship, antara lain sebagai berikut :

\section{Langkah 1:}

Melakukan klasifikasi histori data menggunakan automatic clustering. Semisal nilai $\mathrm{p}=2$, maka hasil interval sebagai berikut:

$$
\begin{aligned}
& \mathrm{u}_{1}=[339227,376202.78) \\
& \mathrm{u}_{2}=[376202.78,413178.57) \\
& \mathrm{u}_{3}=[413178.57,472942.57) \\
& \mathrm{u}_{4}=[472942.57,532706.57) \\
& \mathrm{u}_{5}=[532706.57,538431.78) \\
& \mathrm{u}_{6}=[538431.78,544157) \\
& \mathrm{u}_{7}=[544157,562105.5) \\
& \mathrm{u}_{8}=[562105.5,580054)
\end{aligned}
$$

$$
\begin{aligned}
\mathrm{U}_{9} & =[580054,643376) \\
\mathrm{u}_{10} & =[643376,706698) \\
\mathrm{u}_{11} & =[706698,719166.5) \\
\mathrm{u}_{12} & =[719166.5,731635) \\
\mathrm{u}_{13} & =[731635,778317) \\
\mathrm{u}_{14} & =[778317,825000) \\
\mathrm{u}_{15} & =[825000,840944) \\
\mathrm{u}_{16} & =[840944,856888)
\end{aligned}
$$

Setelah dihitung nilai tengah $m_{i}$ untuk setiap interval $u_{i}$ dengan $1 \leq i \leq 16$, diperoleh hasil sebagai berikut:

$$
\begin{aligned}
& \mathrm{m}_{1}=357714.9 \\
& \mathrm{~m}_{2}=394690.7 \\
& \mathrm{~m}_{3}=443060.6 \\
& \mathrm{~m}_{4}=502824.6 \\
& \mathrm{~m}_{5}=535569.17 \\
& \mathrm{~m}_{6}=541294.39 \\
& \mathrm{~m}_{7}=553131.25 \\
& \mathrm{~m}_{8}=571079.75
\end{aligned}
$$

$$
\begin{aligned}
& \mathrm{m}_{9}=611715 \\
& \mathrm{~m}_{10}=675037 \\
& \mathrm{~m}_{11}=712932.25 \\
& \mathrm{~m}_{12}=725400.75 \\
& \mathrm{~m}_{13}=753976.25 \\
& \mathrm{~m}_{14}=801658.75 \\
& \mathrm{~m}_{15}=832972 \\
& \mathrm{~m}_{16}=848916
\end{aligned}
$$

\section{Langkah 2:}

Dari hasil klasifikasi Langkah 1, maka dapat didefinisikan himpunan fuzzy $\mathrm{A}_{1}, \mathrm{~A}_{2}, \ldots, \mathrm{A}_{16}$. Sebagai berikut:

$$
\begin{aligned}
& A_{1}=1 / u_{1}+0.5 / u_{2}+0 / u_{3}+0 / u_{4}+\ldots+0 / u_{n-1}+ \\
& 0 / u_{16}, \\
& A_{2}=0.5 / u_{1}+1 / u_{2}+0.5 / u_{3}+0 / u_{4}+\ldots+0 / u_{n-1} \\
& +0 / u_{16}, \\
& A_{3}=0 / u_{1}+0.5 / u_{2}+1 / u_{3}+0.5 / u_{4}+\ldots+ \\
& 0 / u_{n-1}+0 / u_{16}, \\
& \cdot \\
& \cdot \\
& \quad . \\
& \quad+1 / u_{16} .
\end{aligned}
$$

Berdasarkan himpunan fuzzy kebutuhan hidup minimum provinsi Jawa Timur dapat difuzzifikasikan seperti Tabel 4.1. Sebagai contoh pada Tabel 2.3 data tahun 2005 adalah 339227 maka pada tahun itu terletak pada interval $u_{1}=[339227,367985.9)$, sehingga data tahun 2005 difuzzifikasi ke dalam $A_{l}$.

Tabel 2.3. Hasil fuzzifikasi

\begin{tabular}{ccc}
\hline Tahun & $\begin{array}{c}\text { Jumlah } \\
\text { (Rupiah) }\end{array}$ & Fuzzifikasi \\
\hline 2005 & 339227 & $A_{1}$ \\
2006 & 580054 & $A_{9}$ \\
2007 & 458755 & $A_{3}$ \\
2008 & 544157 & $A_{7}$ \\
2009 & 706698 & $A_{11}$ \\
2010 & 856888 & $A_{16}$ \\
2011 & 731635 & $A_{13}$ \\
2012 & 731635 & $A_{13}$ \\
2013 & 825000 & $A_{15}$ \\
2014 & 825000 & $A_{15}$ \\
\hline
\end{tabular}

\section{Langkah 3:}

Membangun fuzzy logical relationship. Semisal hasil fuzzifikasi kebutuhan hidup minimum provinsi Jawa Timur tahun 2005 dan 2006 adalah $A_{l}$ dan $A_{11}$. Fuzzy logical relationship yang terbentuk adalah " $A_{l} \rightarrow A_{l l}$ ". Dengan " $A_{l}$ " sebagai current state dan " $A_{11}$ " sebagai next state. Pada Tabel 2.4 ditunjukan hasil fuzzy 
logical relationship kebutuhan hidup minimum provinsi Jawa Timur tahun 2005-2015.

Tabel 2.4. Fuzzy logical relationship kebutuhan hidup minimum provinsi Jawa Timur tahun 2005-2015

$$
\begin{gathered}
A_{1} \rightarrow A_{9} \\
A_{9} \rightarrow A_{3} \\
A_{3} \rightarrow A_{7} \\
A_{7} \rightarrow A_{11} \\
A_{11} \rightarrow A_{16} \\
A_{16} \rightarrow A_{13} \\
A_{13} \rightarrow A_{13} \\
A_{13} \rightarrow A_{15} \\
A_{15} \rightarrow A_{15} \\
A_{15} \rightarrow \# \\
\hline
\end{gathered}
$$

\section{Langkah 4:}

Membangun hasil fuzzy logical relationship dari Langkah 3 menjadi kelompok-kelompok.

Tabel 2.5. Group fuzzy logical relationship kebutuhan hidup minimum provinsi Jawa Timur tahun 2005-2015

\begin{tabular}{c}
\hline Group $1: A_{1} \rightarrow A_{9}$ \\
Group $2: A_{3} \rightarrow A_{7}$ \\
Group $3: A_{7} \rightarrow A_{11}$ \\
Group $4: A_{9} \rightarrow A_{3}$ \\
Group $5: A_{11} \rightarrow A_{16}$ \\
Group $6: A_{13} \rightarrow A_{13}(1), A_{15}(1)$ \\
Group $7: A_{15} \rightarrow A_{15}(1), \#$ \\
Group $8: A_{16} \rightarrow A_{13}(1)$ \\
\hline
\end{tabular}

Fuzzy logial relationship group " $A_{15} \rightarrow A_{15}(1)$, \#” (Group 6) menunjukan ada fuzzy logical relationship:

$$
\begin{gathered}
A_{15} \rightarrow A_{15} . \\
A_{15} \rightarrow \text { \#. }
\end{gathered}
$$

Langkah 5:

Pada bagian ini dilakukan peramalan sesuai dengan prinsip-prinsip Langkah 5. Semisal akan melakukan prediksi tahun 2006 maka melihat tahun sebelumnya yaitu 2005, berdasarkan Tabel 4.1. Tahun 2005 nilai fuzzifikasi kebutuhan hidup minimum adalah $A_{l}$. Dari Tabel 4.3 fuzzy logical relationship " $A_{1} \rightarrow A_{9}$ " pada Group 1 . Nilai peramalan tahun 2006 adalah titik tengah dari $A_{9}$, karena $A_{9}=[580054,643376)$ dan nilai tengah dari $A_{9}$ adalah 611715 maka hasil peramalan tahun 2006 adalah 611715.

Diasumsikan akan melakukan prediksi tahun 2014, berdasarkan Tabel 2.3 tahun diketahui bahwa 2013 memiliki nilai fuzzifikasi $A_{19}$. Dari Tabel 2.4 fuzzy logical relationship " $A_{15} \rightarrow A_{15}$ (1), \#" pada Group 6. Peramalan kebutuhan hidup minimum tahun 2014 dapat dihitung sebagai berikut :

$$
\frac{832972 \times 1+832972 \times 1}{1+1}=832972
$$

Didapatkan hasil peramalan tahun 2014 adalah 832972. Dengan cara yang sama untuk melalukan peramalan tahun 2015 juga melihat tahun sebelumnya yaitu tahun 2014 .

Tabel 2.6. Hasil peramalan kebutuhan hidup minimum provinsi Jawa Timur

\begin{tabular}{ccc}
\hline Tahun & Jumlah (Rupiah) & Peramalan \\
\hline 2005 & 339277 & - \\
2006 & 580054 & 611715 \\
2007 & 458755 & 443061 \\
2008 & 544157 & 553131 \\
2009 & 706698 & 712932 \\
2010 & 856888 & 848916 \\
2011 & 731635 & 754976 \\
2012 & 731635 & 793974 \\
2013 & 825000 & 793974 \\
2014 & 825000 & 832972 \\
2015 & 825000 & 832972 \\
\hline
\end{tabular}

Mean Squere Eror (MSE) radalah suatu metode yang digunakan untuk mengukur selisih pangkat dua antara nilai hasil peramalan dan nilai sebenarnya (Qiu et al, 2015). Pada penelitian ini MSE digunakan sebagai parameter untuk mengukur nilai error, MSE digunakan karena dapat membentuk skala kemiripan hasil peramalan dengan data aktual (Qiu et al, 2015). Pada persamaan 2.7 ditunjukan rumas MSE.

MSE =

$\frac{\sum_{i=1}^{n}(\text { nilai peramalan tahun ke } i-\text { nilai aktual tahun } k e i)^{2}}{n}$,

Dimana $\mathrm{n}$ adalah jumlah keseluruhan tahun yang diramalkan.

Sedangkan untuk menghitung kedekatan antara data aktual dan hasil peramalan digunakan koefisien korelasi ( $r$ ). Dalam melakukan perhitungan nilai $r$ ditunjukan dalam persamaan 2.8 .

$$
\begin{aligned}
& r=\frac{n\left(\sum \bar{Y} Y\right)-\left(\sum \bar{Y}\right)\left(\sum Y\right)}{\sqrt{\left[n\left(\sum \bar{\Upsilon}^{2}\right)-\left(\sum \bar{Y}\right)^{2}\right]\left[n\left(\sum Y^{2}\right)-\left(\sum Y\right)^{2}\right]}}, \\
& \text { Dimana : } \\
& \mathrm{n}=\text { jumlah data. } \\
& \sum \overline{\mathrm{Y}} \quad=\text { jumlah nilai dari variabel } \overline{\mathrm{Y}} \text {. } \\
& \sum \mathrm{Y} \quad=\text { jumlah nilai dari variabel } Y \text {. } \\
& \sum \overline{\mathrm{Y}}^{2} \quad=\text { jumlah nilai dari variabel } \overline{\mathrm{Y}} \\
& \text { pangkat } 2 . \\
& \sum Y^{2}=\text { jumlah nilai dari variabel } Y \\
& \text { pangkat } 2 \text {. } \\
& \left(\sum \overline{\mathrm{Y}}\right)^{2} \quad=\text { jumlah nilai dari variabel } \overline{\mathrm{Y}} \text { yang } \\
& \text { dipangkatkan } 2 . \\
& \left(\sum Y\right)^{2} \quad=\text { jumlah nilai dari variabel } Y \text { yang } \\
& \text { dipangkatkan } 2 . \\
& \sum \overline{\mathrm{Y}} Y \quad=\text { jumlah hasil perkalian variabel } \overline{\mathrm{Y}} \\
& \text { dan } \\
& \text { variabel } \mathrm{Y} \text {. }
\end{aligned}
$$




\section{HASIL DAN PEMBAHASAN}

Pada bagian ini akan dilakukan pengujian terhadap metode peramalan fuzzy logical relationships dan automatic clustering. Pengujian dilakukan terhadap nilai $p$ dalam pembagian jumlah interval automatic clustering. Tabel 3.1 menunjukan hasil peramalan ketola nilai $p=2$.

Tabel 3.1. Hasil peramalam ketika $p=2$ dari automatic clustering

\begin{tabular}{ccc}
\hline Tahun & Aktual & Peramalan \\
\hline 2006 & 580054 & 611715 \\
2007 & 458755 & 443061 \\
2008 & 544157 & 553131 \\
2009 & 706698 & 712932 \\
2010 & 856888 & 848916 \\
2011 & 731635 & 754976 \\
2012 & 731635 & 793974 \\
2013 & 825000 & 793974 \\
2014 & 825000 & 832972 \\
2015 & 825000 & 832972 \\
MSE & 695238077 \\
\hline
\end{tabular}

Dari hasil peramalan menunjukan nilai MSE masih terbilang tinggi sehingga dilakukan pengujian terhadap nilai $p$. Tabel 3.2 menunjukan hasil nilai MSE berdasarkan nilai $p$.

Tabel 3.2. Hasil nilai MSE berdasarkan nilai $p$ dalam automatic clustering

\begin{tabular}{|c|c|}
\hline Nilai P & MSE \\
\hline 10 & 446641356 \\
\hline 15 & 440330664 \\
\hline 20 & 438255481 \\
\hline 25 & 437356023 \\
\hline 30 & 436900406 \\
\hline 35 & 436645507 \\
\hline 40 & 436424904 \\
\hline 45 & 436397083 \\
\hline 50 & 436334824 \\
\hline 55 & 436266661 \\
\hline 60 & 436168766 \\
\hline 65 & 436083668 \\
\hline 70 & 436053461 \\
\hline 75 & 436020525 \\
\hline 80 & 436026655 \\
\hline 85 & 436029069 \\
\hline 90 & 435971361 \\
\hline 95 & 435967283 \\
\hline 100 & 435964587 \\
\hline
\end{tabular}

\section{MSE}

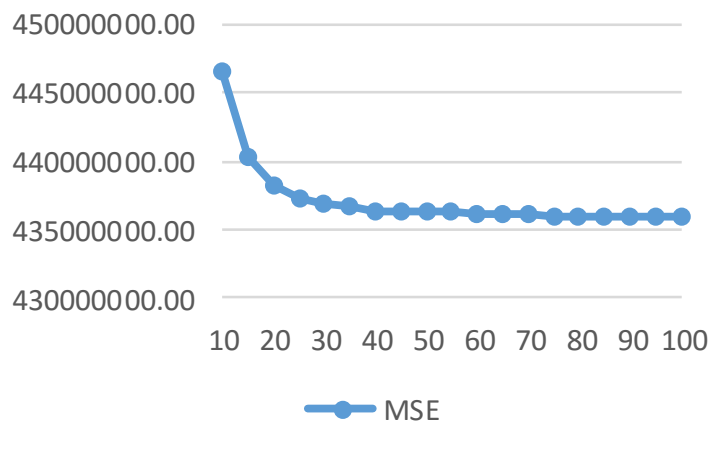

Gambar 3.1. MSE berdasarkan nilai $p$ dalam automatic clustering

Gambar 3.1 sumbu var ketika nilai $p=100$, didapatkan hasil peramalan dari tahun 2005 sampai 2015 antara lain : 580687, 459197, 544336, 706823, 856729, 778631, 778631, 825159,825159 . Selain itu hasil peramalan tahun 2016 adalah 825159 dan nilai memiliki nilai koefisien korelasi sebesar 0.987072916. Gambar 3.2 menunjukan plot perbedaan antara data aktual dan peramalan.

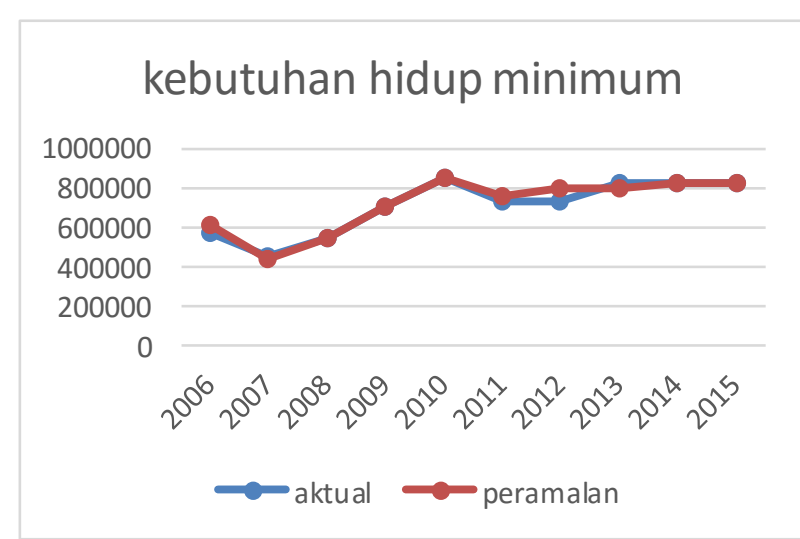

Gambar 3.2. Perbandingan nilai aktual dengan hasil peramalan 


\section{SIMPULAN}

Berdasarkan hasil penelitian dapat ditarik kesimpulan bahwa Metode automatic clustering dapat diterapkan untuk mengklasifikasikan data kebutuhan hidup minimum (KHM) menjadi interval. Nilai $p=100$ memberikan nilai MSE terkecil yaitu 435964587. Metode fuzzy logical relationship dapat diterapkan pada peramalan kebutuhan hidup minimum. Pada tahun 2016 didapatkan nilai peramalan sebesar 825159. Berdasarkan hasil peramalan nilai akurasi yang didapatkan tinggi, memiliki nilai koefisien korelasi sebesar 0.987072916 .

Penelitian selanjutnya akan menerapkan algoritma heuristic seperti particle swarm optimization yang terbukti bisa digunakan untuk meningkatkan akurasi hasil clustering (Wahyuni dkk., 2016)

\section{DAFTAR PUSTAKA}

Askari, S., Montazerin, N. Dan Zarandi, M.H.F., 2015. A clustering based forecasting algorithm for multivariable fuzzy time series using linear combinations of indepent variables. Applied Soft Computing, 35, 151-160.

Aznarte, J.L., Fdez, J.A. Azofra, A.A. dan Benitez, J. M., 2012. Financial time series forecasting with a bio-inspired fuzzy model.Expert Systems with Applications, 39, 12302-12309.

Badan Pusat Statistika, 2016. [data] Kebutuhan hidup minimum (online). Tersedia di: <http:// https://www.bps.go.id/linkTableDinamis/ view/id/1212/> [Diakses 26 juli 2016]

Chen, S.M. dan Chen, C.D., 2011. Handling forecasting problems based on high-order fuzzy logical relationships. Expert Systems with Applications, 38, 3856-3864.

Chen, S.M. dan Chen, S.W., 2015. Fuzzy forecasting based on two-factors secondorder fuzzy-trend logical relationship group and the probabilites of tren of fuzzy logical relatonships. IEEE Transactions on Cybernetics, Vol 45, No. 3.

Chen, S.M. dan Tunawijaya, K., 2011. Multivariate fuzzy forecasting based on fuzzy time series and automatic clustering technique. Expert System with Applications, 38, 10594-10605.

Cheng, S.H., Chen, S.M. dan Jian, W.S., 2015. A novel fuzzy time series forecasting method based on fuzzy logical relationships and similarity measures. IEEE International Conference on
Systems, Man, and Cybernetics, 978(1), 4799-8697.

Cheng, S.H., Chen, S.M. dan Jian, W.S., 2016. Fuzzy time series forecasting based on fuzzy logical relationships and similarity measures. Information Sciences, 327, 272287.

Garcia, A.J. dan Flores, W.G., 2016. Automatic clustering using nature-inspired metaheuristics : a survey. Applied Soft Computing, 41, 192-213.

Hung, W.H. dan Kang, S.C.J, 2014. Automatic clustering method for real-time contruction simulation. Advanced Engineering Informatic, 28, 138-152.

Liu, T.K., Chen, Y.P. dan Chou, J.H., 2011. Extracting fuzzy relations in fuzzy time series model based on approximation concepts. Expert Systems with Applications, 2011, 11624-11629.

Qiu, W., Liu, X. dan Li, H., 2011. A generalized method for forecasting based on fuzzy time series. Expert Systems with Applications, 38, 10446-10453.

Qiu, W., Zhang, P. dan Wang, Y., 2015. Fuzzy time series forecasting model based on automatic clustering techniques and generalized fuzzy logical relationship. Hindawi Publishing Corporation Mathematical Problems in Engineering, 962597.

Republik Indonesia. 2012. Undang-Undang No. 13 Tahun 2012 Tentang Komponen dan Pelaksanaan Tahapan Pencapaian Kebutuhan Hidup Layak. Peraturan Mentri Tenaga Kerja dan Transmigrasi RI Tahun 2015, No. 13. Sekretariat Negara. Jakarta.

Saha, S. dan Bandyopadhayay, S., 2013. A generalized automatic clustering algorithm in a multiobjective framework. Applied Soft Computing, 13, 89-108.

Song, Q. dan Chissom, B.S., 1993. Fuzzy time series and its models. Fuzzy time series, Vol. 54, Issue 3.

Song, Q. dan Chissom, B.S., 1993. Forecasting enrollment with fuzzy time series - part I. Fuzzy Sets and Systems, Vol. 54, Issue 1.

Song, Q. dan Chissom, B.S., 1994. Forecasting enrollments with fuzzy time series - part II. Fuzzy Sets and Systems, Vol. 62, Issue 1 .

Wahyuni, I, Auliya, YA, Rahmi, A \& Mahmudy, WF 2016, 'Clustering Nasabah Bank Berdasarkan Tingkat Likuiditas Menggunakan Hybrid Particle Swarm Optimization dengan K-Means', Jurnal 
102 Jurnal Teknologi Informasi dan Ilmu Komputer (JTIIK), Vol. 3, No. 2, Juni 2016, hlm. 94-102

Ilmiah Teknologi dan Informasi ASIA (JITIKA), vol. 10, no. 2, pp. 24-33.

Wang, G.P., Chen, S.Y., Yang, X. dan Liu, Jun., 2014. Modeling and analyzing of conformity behavior : A fuzzy logic approach. Optik, 125, 6594-6598.

Wang, W. dan Liu, X., 2015. Fuzzy forecasting based on automatic clustering and axiomatic fuzzy set classification. Information Sciences, 294, 78-94. 